\title{
Morphology and digitally aided morphometry of the human paracentral lobule
}

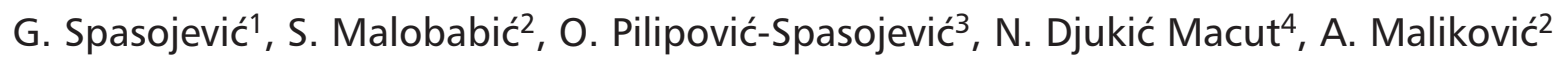 \\ ${ }^{1}$ Department of Anatomy, Faculty of Medicine, University of Banja Luka, Banja Luka, Republic of Srpska, \\ Bosnia and Herzegovina \\ Institute of Anatomy "Dr Niko Miljanić", Faculty of Medicine, University of Belgrade, Belgrade, Serbia \\ ${ }^{3}$ Department of Physical Medicine and Rehabilitation "Dr Miroslav Zotović", Banja Luka, Republic of Srpska, \\ Bosnia and Herzegovina \\ ${ }^{4}$ Department of Anatomy, Faculty of Medicine, University of Kosovska Mitrovica (Priština), Serbia
}

[Received 13 October 2012; Accepted 17 December 2012]

\begin{abstract}
The human paracentral lobule, the junction of the precentral and postcentral gyri at the medial hemispheric surface, contains several important functional regions, and its variable morphology requires exact morphological and quantitative data. In order to obtain precise data we investigated the morphology of the paracentral lobule and quantified its visible (extrasulcal) surface. This surface corresponds to commonly used magnetic resonance imaging scout images. We studied 84 hemispheres of adult persons (42 brains; 26 males and 16 females; 20-65 years) fixed in neutral formalin for at least 4 weeks. The medial hemispheric surface was photographed at standard distance and each digital photo was calibrated. Using the intercommissural line system (commissura anterior-commissura posterior or (A-CP line), we performed standardised measurements of the paracentral lobule. Exact determination of its boundaries and morphological types was followed by digital morphometry of its extrasulcal surface using AutoCAD software. We found two distinct morphological types of the human paracentral lobule: continuous type, which was predominant (95.2\%), and rare segmented type (4.8\%). In hemispheres with segmented cingulate sulcus we also found the short transitional lobulo-limbic gyrus (13.1\%). The mean extrasulcal surface of the left paracentral lobule was significantly larger, both in males (left $6.79 \mathrm{~cm}^{2}$ vs. right $5.76 \mathrm{~cm}^{2}$ ) and in females (left $6.05 \mathrm{~cm}^{2}$ vs. right $5.16 \mathrm{~cm}^{2}$ ). However, even larger average surfaces in males were not significantly different than the same in females. Reported morphological and quantitative data will be useful during diagnostics and treatment of pathologies affecting the human paracentral lobule, and in further studies of its cytoarchitectonic and functional parcellations. (Folia Morphol 2013; 72, 1: 10-16)
\end{abstract}

Key words: paracentral lobule, anatomy, encephalometry, human brain, left-right asymmetry, sex differences

\section{INTRODUCTION}

The human paracentral lobule ( $\mathrm{PCL})$, the convolution at the medial hemispheric surface, connects medial portions of the precentral and postcentral gyri. In
Terminologia Anatomica the term PCL (lobulus paracentralis) was used twice and separately in order to indicate the anterior and posterior paracentral gyri [5]. Morphology and boundaries of the PCL are determined

Address for correspondence: Prof. Dr. S. Malobabić, Institute of Anatomy "Dr Niko Miljanić”, Faculty of Medicine, Dr Subotica 4/II، 11000 Belgrade, Serbia, tel: 381112684 259, fax: 381112684 053, e-mail: editsources1@yahoo.com 
by its limiting sulci, while its superior boundary corresponds to the superior margin of the hemisphere. Cingulate sulcus is the crucial anatomical landmark that bounds the PCL, either by its subfrontal segment (separates $\mathrm{PCL}$ and cingulate gyrus) or by its constantly present terminal branch (marginal ramus), which separates the PCL and precuneus. In cases of segmented cingulate sulcus there is a short transitional lobulolimbic gyrus, which may complicate definition of the PCL boundaries [22]. In a functional MRI study Desikan et al. [3] delineated the PCL as the structure located posterior to the medial (superior) frontal gyrus (or the precentral gyrus when visible), anterior to the precuneus (or the postcentral gyri when visible), superior to the cingulate gyrus, and inferior to the superior hemispheric border. There is also a report that the PCL extends from the ascending and descending paracentral sulci anteriorly, to the terminal "up-swing" of the cingulate sulcus posteriorly [19]. Anterior to the PCL, along the medial frontal gyrus, lies the supplementary motor area (SMA), but its morphological boundary was not defined in the literature.

The anterior two thirds of the PCL (medial surface of the precentral gyrus or anterior paracentral gyrus) belong to Brodmann area 4 (BA4) [2]. The thick and agranular cortex of BA4 in the PCL is a part of the primary motor area representing the muscles of the leg and foot [4] and the urinary bladder [9], but the leg area of the primary motor cortex may extend more caudal from the central sulcus toward the marginal ramus of cingulate sulcus [10]. The posterior third of the PCL (medial surface of the postcentral gyrus or posterior paracentral gyrus) contains $\mathrm{BA} 3, \mathrm{BA} 2$, and $B A 1$, and inferior to these is the part of BA5 [2]. In the $\mathrm{PCL}$, the granular cortex of $\mathrm{BA} 3, \mathrm{BA} 2$, and $\mathrm{BA} 1$ reflects the primary somatosensory representation of the leg and foot [4]. Interestingly, Penfield and Roberts [17] did not show any representation of the genital organs within the PCL in his famous schemes, which is shown in numerous anatomical textbooks.

There is a viewpoint that morphological boundaries of cytoarchitectonic areas do not correspond to brain sulci and gyri [2]. The portion of the sensorimotor cortex with the most interindividual variability is the extension of areas BA4 and BA3 onto the mesial face of the hemisphere in the PCL $[19,25]$. Therefore, in the studies of the consistency of the PCL cytoarchitectonic borders across the brains with different sulcal patterns, the brain selection must involve related sulcal or gyral morphology [6, 24].

We investigated the morphology of the human PCL because morphological data improve diagnos- tics and functional studies, and enable the quantification of genetic or environmental influences to the morphology of the human brain $[1,18]$. The aims of our study were to standardise the boundaries of the human $\mathrm{PCL}$, to define its morphological variability, to quantify and investigate morphological left-right asymmetries of the visible (exstrasulcal) surface of the $\mathrm{PCL}$, as well as to estimate the potential morphological sex differences.

\section{MATERIALS AND METHODS}

This study included 84 brain hemispheres (42 brains) without visible pathological changes or neuropsychiatric history, from the collection of the Belgrade Institute of Anatomy "Dr Niko Miljanić", which were treated in accordance with the Ethical Principles for Medical Research Involving Human Subjects [27]. Brains of adult persons of both sexes (26 males and 16 females, aged between 20-65 years) were fixed by basilar suspension in neutral formalin for at least 4 weeks. After, midsagittal brain section meninges were carefully removed and the medial hemispheric surface of each investigated brain was exposed. Medial hemispheric surfaces were photographed perpendicular to its plane at a standard distance of $50 \mathrm{~cm}$, using a digital camera of high resolution (8 Mpx). Each digital photo was calibrated in accordance with the marked lines ( $X$ and $Y$ ) and further used for the standardised measurements of the PCL using AutoCAD software (AutoCAD 2009, version C.56.0, Autodesk Corporation).

The intercommissural or the CA-CP line (here, the $X$-axis along the sagittal plane, Fig. 1) was defined as the line connecting the most prominent superior point of the anterior commissure (CA) and the most prominent inferior point of the posterior commissure (CP) [23], while the vertical line (here, the Yaxis, Fig. 1) was defined as the perpendicular bisector (the line that lies under $90^{\circ}$ to the middle point of the intercommissural line) (Fig. 1).

\section{Definition of the PCL boundaries (Fig. 1)}

The posterior boundary of the PCL was the constant marginal ramus of the cingulate sulcus. The Inferior boundary of the PCL was the cingulate sulcus. In cases of segmented sulcus cinguli, we defined this boundary by the horizontal X1 line (parallel to the CA-CP line), which connects the main segments of the cingulate sulcus across the region of its missing part between the PCL and the cingulate gyrus. The anterior boundary of the PCL was standardised using the intercommissural or CA-CP line [23] due to 


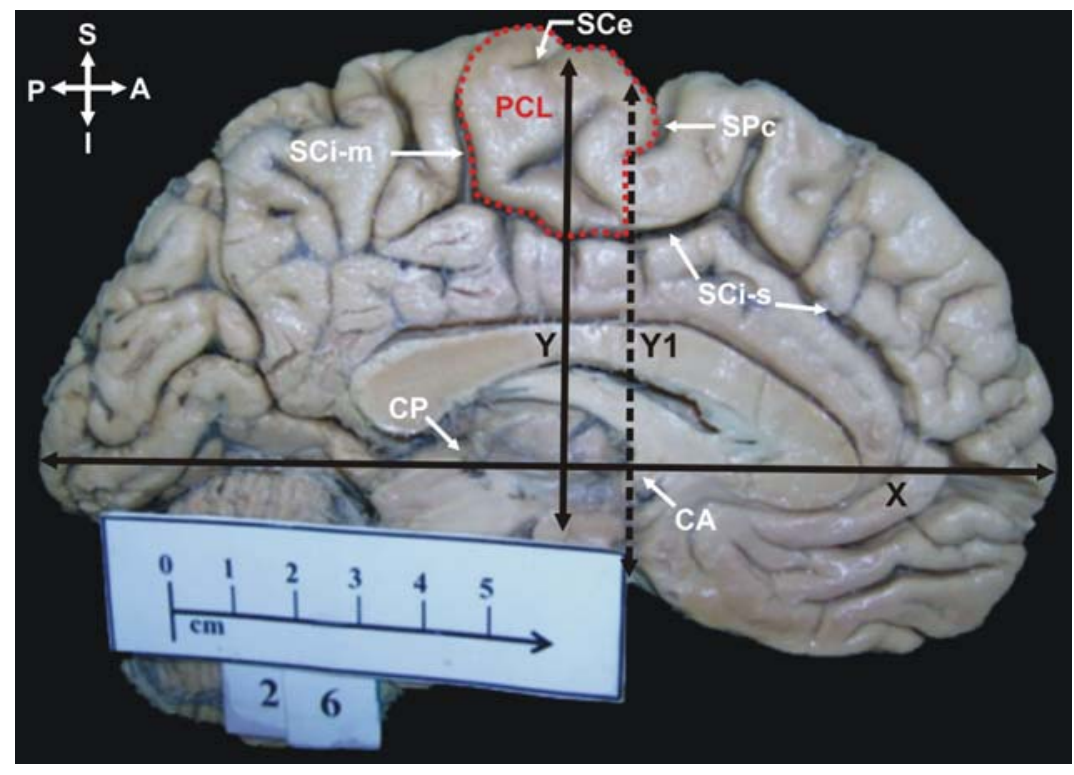

Figure 1. Boundaries of the paracentral lobule (PCL) in respect to the intercommissural or CA-CP line; CA - commissura anterior; $\mathrm{CP}$ - commissura posterior; $X-C A-C P$ line or axis along the sagittal plane; $Y$ - vertical line intersecting the middle of $\mathrm{CA} / \mathrm{CP}$ line; $\mathrm{Y} 1$ line that defines the anterior boundary of the PCL (see Methods section); SCe central sulcus, medial part; SPc — precentral sulcus; SCi-s - cingulate sulcus, subfrontal part; SCi-m — cingulate sulcus, marginal part. Left hemisphere. Orientation: A - anterior; $\mathrm{P}$ - posterior; $\mathrm{S}$ - superior; I - inferior. a total absence of clear morphological landmarks (Fig. 1). Using this means of standardisation, the anterior boundary of the PCL was defined as the vertical line (line $\mathrm{Y} 1$ parallel to $\mathrm{Y}$ ), extending from the medial end of the precentral sulcus to the cingulate sulcus. The surface located posterior to the $\mathrm{Y} 1$ line was referred to as the PCL.

In a few cases, when the precentral sulcus did not reach the medial surface, we extended its direction by an imaginary straight line that reached the superior border of the hemisphere, and then used the corresponding vertical $\mathrm{Y} 1$ line to the cingulate sulcus. The superior boundary of the PCL was the superior border of the hemisphere.

\section{Statistical analysis}

Statistical analysis was performed using descriptive statistics. The measured surfaces of the PCL (in $\mathrm{cm}^{2}$ ) were compared between hemispheres (interhemispheric differences) and genders (sex differences) using a t-test. This parametric method for the differences was used because our numerical variables followed the normal distribution, which was tested by the Kolmogorov-Smirnov test. An obtained $p$ value less than 0.05 was considered significant.

\section{RESULTS}

We classified morphological types of the PCL into continuous and segmented types. The continuous type of PCL was specific due to the presence of its constituent precentral and postcentral gyri, which were not completely segmented by the sulci. This type was found in most of the investigated brains (Fig. 2, Table 1). The segmented type of PCL was characterised by the presence of the constituent gyri, which were completely separated by the sulci (Fig. 3, Table 1). This type we found in only $4.8 \%$ of hemispheres.

Additionally, hemispheres with segmented cingulate sulcus (13.1\% of cases) had the lobulo-limbic transitional gyrus interposed between the PCL and cingulate gyrus (Fig. 4).

Measurements of the extrasulcal surface of the PCL, with noted differences related to the side of the hemisphere and sex, are presented in Tables 2 and 3. In the total sample, the mean surface of the extrasulcal cortex of the left PCL $\left(6.51 \mathrm{~cm}^{2}\right)$ was statistically significantly larger $(p<0.05)$ than the extrasulcal surface of the right PCL $\left(5.37 \mathrm{~cm}^{2}\right)$ (Table 2).

In males, the average surface of the left PCL extrasulcal cortex $\left(6.79 \mathrm{~cm}^{2}\right)$ was statistically significantly larger $(p<0.05)$ in relation to the right PCL $\left(5.76 \mathrm{~cm}^{2}\right)$ (Table 3$)$. In females, the average surface of the left PCL extrasulcal cortex $\left(6.05 \mathrm{~cm}^{2}\right)$ was larger than the right $P C L\left(5.16 \mathrm{~cm}^{2}\right)$, and this difference was also statistically significant $(p<0.05)$.

After comparing the extrasulcal cortical surface areas of the PCL between males and females (separately the left with the left, and the right with the right), we did not find statistically significant sex differences ( $p>0.05)$.

We can conclude that the extrasulcal (visible) cortical surface of the PCL in both sexes was statistically significantly larger in left hemispheres, which indicates a certain, probably basic, type of left-right morpho- 

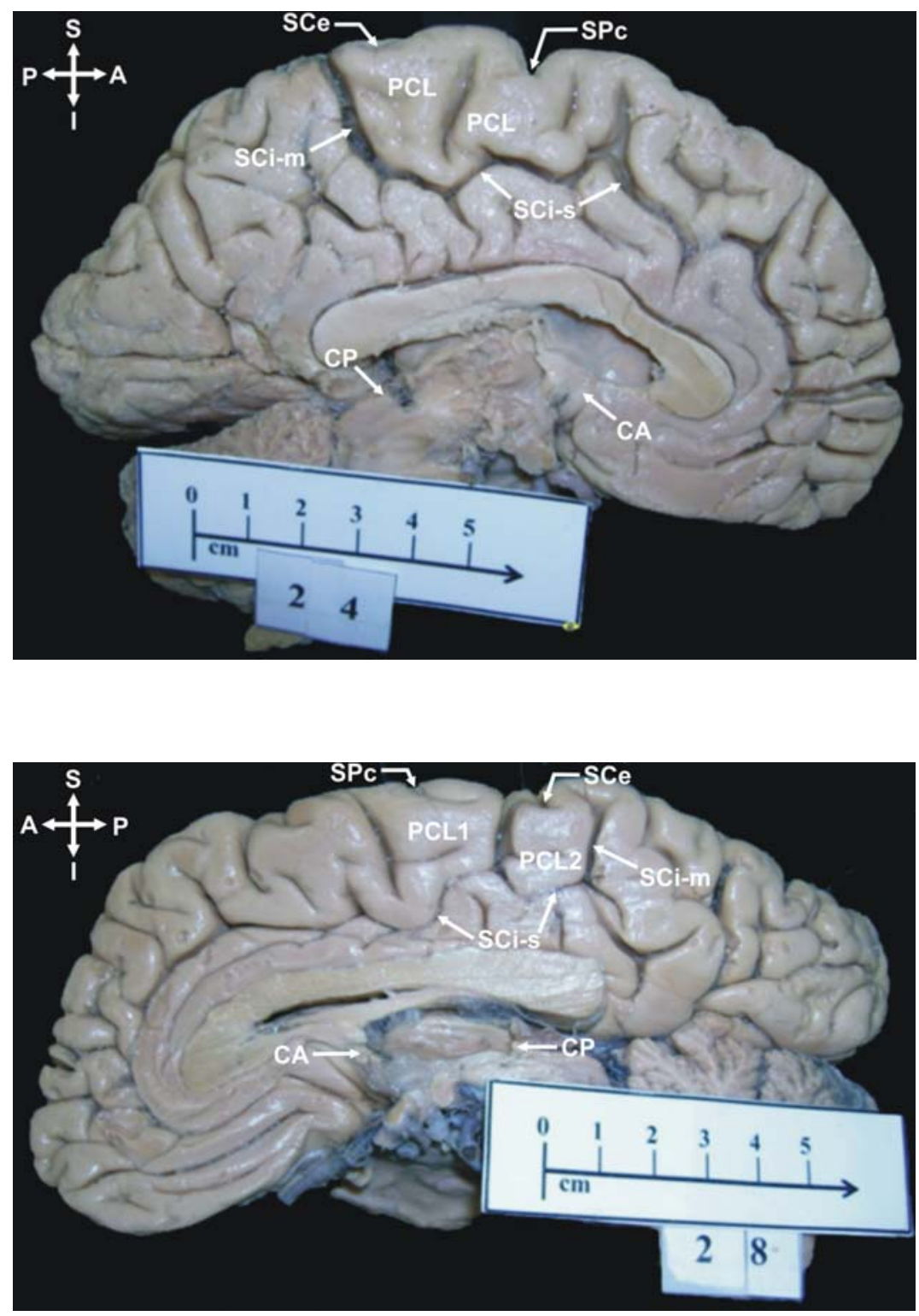

Figure 2. Paracentral lobule (PCL) - continuous type (precentral and postcentral gyri are continuous, or not completely separated by sulci), found in $95.2 \%$ of cases; CA — commissura anterior; $\mathrm{CP}$ - commissura posterior; $\mathrm{SCe}$ - central sulcus, medial part; SPc — precentral sulcus; SCi-s - cingulate sulcus, subfrontal part; SCi-m - cingulate sulcus, marginal part. Left hemisphere. Orientation: $\mathrm{A}$ - anterior; $\mathrm{P}$ - posterior; $S$ - superior; I - inferior.
Table 1. Morphological types of the paracentral lobule (PCL). Sample: 42 brains, 84 hemispheres

\begin{tabular}{ccc}
\hline PCL type & $\begin{array}{c}\text { Number of } \\
\text { hemispheres }\end{array}$ & $\begin{array}{c}\text { Frequency } \\
(\%)\end{array}$ \\
\hline Continuous & 80 & 95.2 \\
Segmented & 4 & 4.8 \\
\hline
\end{tabular}

logical asymmetry. However, despite the larger surface area of extrasulcal cortex of the PCL in males, we did not find significant sex differences of this value.

\section{DISCUSSION}

Due to the absence of a clearly visible anterior boundary of the $\mathrm{PCL}$, we standardised it using the intercommissural (CA-CP) line [23]. It is well known that conventional lines are used in delineation even of the brain lobes, including the boundary between the frontal and parietal lobes passing just through the PCL. The CA-CP or similar exact systems of lines for delineation of the PCL or other brain areas are often used $[11,13,19]$ in order to increase precision of data. Similar to our method, defined boundaries of the human SMA using magnetic resonance imaging (MRI) study were: the cingulate sulcus, vertical axis of the anterior commissure, and the extension of the central sulcus onto the mesial surface [10]. The paracentral sulcus, which is anterior to the precentral sulcus, contains the supplementary eye area $[11,16,19]$ and therefore we did not consider it as a potential anterior boundary of the PCL. In 


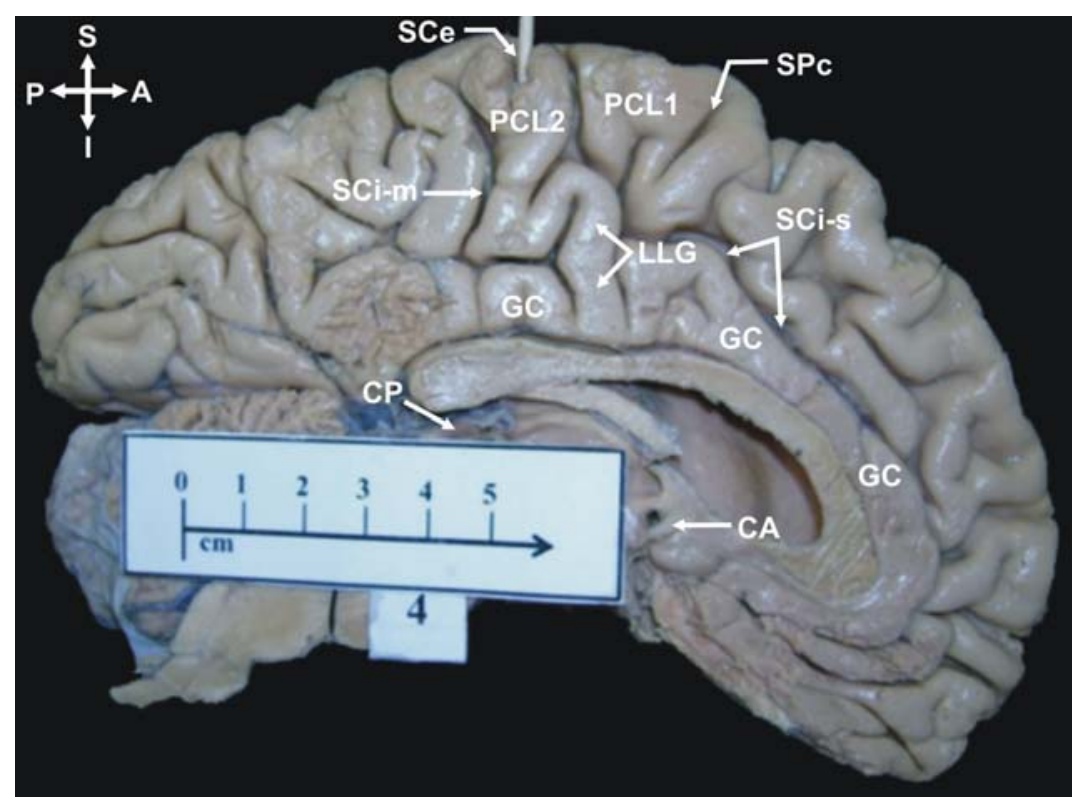

Figure 4. Paracentral lobule (PCL) segmented type (segmented into anterior - PCL1, and posterior - PCL2 segments) and the lobulo-limbic transitional gyrus (LLG). The LLG (found in $13.1 \%$ of cases) is interposed between the PCL2 and cingulate gyrus (GC); $\mathrm{CA}$ - commissura anterior; $\mathrm{CP}$ - commissura posterior; $\mathrm{SCe}$ - central sulcus, medial part (probe placed in the sulcus); $\mathrm{SPc}$ precentral sulcus; $\mathrm{SCi}$-s - cingulate sulcus, subfrontal part; SCi-m - cingulate sulcus, marginal part. Left hemisphere. Orientation: $\mathrm{A}$ - anterior; $\mathrm{P}$ - posterior; $S$ - superior; I - inferior.

Table 2. Extrasulcal surface of the paracentral lobule (PCL). Total sample: 42 brains, 84 hemispheres with surfaces (mean with the range of minimal and maximal values), standard deviations (SD) and coefficients of variation (CV)

\begin{tabular}{lcccc}
\hline PCL & Hemispheres & Mean $\left[\mathbf{c m}^{2}\right]$ & SD $\left[\mathbf{c m}^{2}\right]$ & CV (\%) \\
\hline Right & 42 & $5.35(2.41-9.08)$ & 1.34 & 25.0 \\
Left & 42 & $6.51(4.37-9.68)$ & 1.25 & 19.2 \\
\hline
\end{tabular}

Table 3. Extrasulcal surface of the paracentral lobule in males and females with surfaces (mean with the range of minimal and maximal values), standard deviations (SD) and coefficients of variation (CV)

\begin{tabular}{lccccc}
\hline & \multicolumn{2}{c}{ Males (52 hemispheres) } & & \multicolumn{2}{c}{ Females (32 hemispheres) } \\
\cline { 2 - 3 } \cline { 6 - 6 } & Right & Left & & Right & Left \\
\hline Mean $\left[\mathrm{cm}^{2}\right]$ & $5.76(3.41-9.08)$ & $6.79(4.76-9.68)$ & & $5.16(3.44-7.55)$ & $6.05(4.37-7.93)$ \\
$\mathrm{SD}\left[\mathrm{cm}^{2}\right]$ & 1.47 & 1.34 & & 1.07 & 0.96 \\
$\mathrm{CV}(\%)$ & 25.5 & 19.7 & & 20.7 & 15.86 \\
\hline
\end{tabular}

cases of segmented cingulate sulcus, between the supratruncal region of the cingulate gyrus and the $\mathrm{PCL}$, in $37 \%$ of cases [22] there is one short lobulolimbic transitional gyrus, but in our sample it was found in only $13.1 \%$ of cases.

Within the posterior third of the PCL (BA3, BA1, and $B A 2$ ) there is somatosensory representation of the foot and leg [4], but primary sensory representation of the human penis lies on the convexity of the postcentral gyrus in an area overlapping with the representation of the lower abdominal wall [14]. Inferior and posterior to $B A 3, B A 1$, and $B A 2$, there is a part of BA5, and therefore the posterior PCL belongs to the medial part of the human superior parietal cortex (BA5 and BA7). The anatomical landmarks of cytoarchitectonic areas $5 \mathrm{~L}$ (medial and posterior to BA2), 7A, and 7P showed significant interhemispheric differences reaching the $\mathrm{PCL}$ to variable extents, which may be functionally relevant [20]. Activation of the posterior PCL (BA5) by somatosensory stimulation in humans is related to attention processes [8], probably because the most highly efficient connector hubs of the structural core of the cerebral cortex bilaterally include the 
parts of the cingulate gyrus, the $\mathrm{PCL}$, and the precuneus [12].

The central portion of the PCL occupies the medial portion of BA4 (primary somatomotor cortex) without limiting the sulcal landmark, and without consistent association between the individual sulci and cytoarchitectonic borders [6]. The cytoarchitectonic borders between BA4 and BA3 in the PCL showed considerable interindividual variation in the way that a significant portion of BA4 compared to a very small portion of $\mathrm{BA} 3$ extended into the $\mathrm{PCL}$ [25]. Contrary to the PCL, the central sulcus provides a reliable anatomical landmark of the cytoarchitectonic borders of the dorsolateral sensorimotor cortex $[19,25]$. Also, the areal location of cytoarchitectonic mesial area 6 (SMA proper) is remarkably constant despite different sulcal patterns among the hemispheres. Its caudal sector is in the middle of the PCL just rostral to the somatic koniocortex, and the other rostral sector is next to BA4 [24]. In the SMA, activation while subjects moved their hand, shoulder, or leg was found. This activation was found above the sulcus cinguli, and anteriorly within the $\mathrm{PCL}$, most commonly close to or within the paracentral sulcus $[6,10]$. In human SMA, the mesial motor representation has an ordered organisation with the leg located caudally and the arm located rostrally [19].

We believe that the findings about the role of the PCL in micturition control [9] should be considered in the context of its morphological variability, close relationships to the medial frontal and anterior cingulate cortex, and the absence of its clear anterior boundaries. The presence of segmented PCL, which we found only in $4.8 \%$ of hemispheres, correlates with the report that one subject with interruption and duplication of the cingulate sulcus had the blood flow increase in the SMA located more rostrally [10].

The extrasulcal surface is clearly visible on routine MRI scout images, and our morphometric data can be used for delineation of the PCL and for its further studies. Our finding of significantly larger extrasulcal surface of the left PCL $\left(6.51 \mathrm{~cm}^{2}\right) \mathrm{com}$ pared to right PCL $\left(5.35 \mathrm{~cm}^{2}\right)$ corresponds to the predominance of right-handed people in the population (90-95\%), i.e. dominance of the left hemisphere for many important functions [26]. Also, the region of the left $\mathrm{PCL}$ showed greater activation during the knee task compared with the ankle tasks [15], and also when subjects performed saccadic eye movements [11]. The predominance of continuous morphological type that we found $(95.2 \%)$ confirms that primary and secondary areas exhibit less variability than higher order cortical areas [7], but we do not know if the same is true for morphometric differences (variability in areal sizes). We did not find statistically significant differences in the extrasulcal surface area of the PCL between males and females, but morphological and morphometric gender differences have various aspects and are more complex than usually expected [21].

We found two distinct morphological types of the human PCL with a predominance of the continuous type (95.2\% of cases), the presence of the lobulo-limbic gyri in $13.1 \%$ of cases, and significantly larger PCL extrasulcal surface on the left hemispheres, both in males and females. Our precise morphological data obtained by digital morphometry, combined with additional reports about variable cytoarchitectonic and functional properties of PCL, indicate a need for very careful neuroimaging, functional diagnostics, and surgical planning in the region of the human paracentral lobule.

\section{ACKNOWLEDGEMENTS}

This study was supported by grant Nr. 175030 of the Ministry of Education, Science, and Technological Development, Republic of Serbia.

\section{REFERENCES}

1. Baare WFC, Hulshoff HE, Boomsma D, Posthuma D, de Geus EJC, Shnack HG, van Haren NEM, van Oel CJ, Kahn RS (2001) Quantitative genetic modelling of variation in human brain morphology. Cerebral Cortex, 11: 816-824.

2. Brodmann K (1925) Vergleichende Lokalizationslehre der Grosshirnrinde. 2. Aufl., Verlag JA Barth, Leipzig, pp. 43-69.

3. Desikan SR, Segonne F, Fischl B, Quinn TB, Dickerson CB, Blacker D, Buckner LR, Dale MA, Maguire RP, Hyman TB, Albert SM, Killiany JR (2006) An automated labeling system for subdividing the human cerebral cortex on MRI scans into gyral based regions of interest. Neurolmage, 31: 968-980.

4. Duvernoy HM (1991) The human brain; surface, three-dimensional sectional anatomy and MRI. Springer-Verlag, Wien-New York, pp. 28-29.

5. FCAT-Federative Committee on Anatomical Terminology (1998) Terminologia Anatomica. Thieme, Stuttgart-New York, p. 126.

6. Fink RG, Frackowiak SJR, Pietrzyk U, Passingham ER (1997) Multiple nonprimary motor areas in the human cortex. J Neurophysiol, 77: 2164-2174.

7. Fischl B, Rajendran N, Busa E, Augustinack J, Hinds OBT, Yeo T, Mohlberg H, Amunts K, Zilles K (2008) Cortical folding patterns and predicting cytoarchitecture. Cerebral Cortex, 18: 1973-1980.

8. Fors N, Merlet I, Vanni S, Himiiliinen M, Hari MF (1996) Activation of human mesial cortex during somatosensory target detection task. Brain Res, 734: 229-235. 
9. Fowler CJ, Griffiths DC, de Groat W (2008) The neural control of micturition. Nat Rev Neurosci, 9: 453-466.

10. Grafton TS, Fagg HA, Woods PR, Arbib AM (1996) Functional anatomy of pointing and grasping in humans. Cerebral Cortex, 6: 226-237.

11. Grosbras MH, Lobel E, van de Moortele PF, Le Bihan D, Berthoz A (1999) An anatomical landmark for the supplementary eye field in human revealed with functional magnetic resonance imaging. Cerebral Cortex, 9: 705-711.

12. Hagmann $P$, Cammoun L, Gigandet $X$, Meuli R, Honey CJ, Wedeen VJ, Sporns O (2008) Mapping the structural core of human cerebral cortex. PLoS Biol, 6: e159.

13. Hamani C, Mayberg H, Snyder B, Giacobbe P, Kennedy S, Lozano A (2009) Deep brain stimulation of the subcallosal cingulate gyrus for depression: anatomical location of active contacts in clinical responders and suggested guideline for targeting. J Neurosurg, 111: 1209-1215.

14. Kell AC, von Kriegstein $K$, Rosler A, Kleinschmidt A, Laufs $H$ (2005) The sensory cortical representation of the human penis: revisiting somatotopy in the male homunculus. J Neurosci, 25: 5984-5987.

15. Newton MJ, Dong Y, Hidler J, Plummer-D'Amato P, Marehbian J, Albistegui-DuBois MR, Woods PR, Dobkin HB (2008) Reliable assessment of lower limb motor representations with $\mathrm{fMRI}$ : use of a novel MR compatible device for real-time monitoring of ankle, knee and hip torques. Neuroimage, 43: 136-146.

16. Ono M, Kubik S, Abernathey DC (1990) Atlas of cerebral sulci. Georg Thieme Verlag Stuttgart-New York.

17. Penfield W, Roberts L (1959) Speech and brain-mechanisms. Princeton University Press, Princeton, New Jersey.

18. Peper JS, Brouwer RM, Boomsma DI, Kahn RS, Hulshoff PHE (2007) Genetic influences on human brain structure: a review of brain imaging studies in twins. Hum Brain Mapp, 28: 464-473.
19. Rademacher J, Bürgel U, Geyer S, Schormann T, Schleicher A, Freund HJ, Zilles K (2001) Variability and asymmetry in the human precentral motor system. A cytoarchitectonic and myeloarchitectonic brain mapping study. Brain, 124 (Part 11): 2232-2258.

20. Scheperjans F, Hermann K, Eickhoff BS, Amunts K, Schleicher A, Zilles K (2008) observer-independent cytoarchitectonic mapping of the human superior parietal cortex. Cerebral Cortex, 18: 846-867.

21. Spasojević G, Malobabić S, Suscević $D$, Miljković $Z$ (2004) Morphometric variability of precuneus in relation to gender and the hemisphere of human brain. Vojnosanitetski Pregled, 61: 365-370.

22. Stanczyk $\sqcup$ (1983) Variation of the gyrus and sulcus cinguli in phylo and ontogenesis. Folia Morphol, 42: 243-259.

23. Talairach J, Tournoux P (1988) Co-planar Stereotaxic atlas of the human brain. Thieme Medical Publishers, New York.

24. Vorobiev V, Govoni P, Rizzolatti G, Matelli M, Luppino G (1998) Parcellation of human mesial area 6: cytoarchitectonic evidence for three separate areas. Eur J Neurosci, 10: 2199-2203.

25. White EL, Andrews JT, Hulette C, Richards A, Groelle M, Paydarfar J, Purves D (1997) Structure of the human sensorymotor system. I: morphology and cytoarchitecture of the central sulcus. Cerebral Cortex, 7: 18-30.

26. Witelson SF, Kigar DL (1988) Asymmetry in brain function follows asymmetry in anatomical form: gross, microscopic, postmortem and imaging studies. In: Boller F, Grafman J eds. Handbook of neuropsychology. Vol. 1. Chapter 6. Elsevier, New York, pp. 111-142.

27. World Medical Association Declaration Of Helsinki: Ethical Principles for Medical Research Involving Human Subjects, 59th WMA General Assembly, Seoul, October 2008 Available at: http://www.wma.net/en/30publications/10policies/b3/index.html, Accessed 19 Jan 2010. 